\title{
Hubungan Sarana Sanitasi, Perilaku Penghuni, dan Kebiasaan Cuci Tangan Pakai Sabun (CTPS) oleh Ibu dengan Kejadian Pendek (Stunting) pada Batita Usia 6-24 Bulan di Wilayah Kerja Puskesmas Harapan Baru, Samarinda
}

\author{
Herawati $^{*}$, Andi Anwar ${ }^{2}$, Dina Lusiana Setyowati ${ }^{3}$ \\ ${ }^{1}$ Faculty of Public Health, Universitas Mulawarman \\ ${ }^{2}$ Departement of Environmental Health, Faculty of Public Health, Universitas Mulawarman \\ ${ }^{3}$ Departement of Occupational Health, Faculty of Public Health, Universitas Mulawarman \\ *Corresponding author: herawatibalikpapan@gmail.com
}

Info Artikel : Diterima 11 Februari 2019 ; Disetujui 11 Desember 2019 ; Publikasi 1 April 2020

\begin{abstract}
ABSTRAK
Latar belakang: Sebuah daerah dinyatakan memiliki permasalahan kesehatan masyarakat jika memiliki prevalensi stunting sebesar 20\% atau lebih. Prevalensi stunting di Kalimantan Timur mencapai $29,6 \%$ dan didominasi oleh anak usia dibawah dua tahun pada tahun 2017. Samarinda memiliki prevalensi stunting melebihi $20 \%$. Terdapat banyak faktor yang dapat memengaruhi kejadian stunting, tetapi dibutuhkan penelitian terkait sarana sanitasi, perilaku penghuni dan kebiasaan CTPS ibu dengan kejadian stunting. Penelitian ini bertujuan untuk membuktikan ada/tidaknya hubungan antara kualitas sarana sanitasi, perilaku penghuni, dan kebiasaaan CTPS ibu dengan kejadian stunting pada anak kelompok usia 6-24 bulan di wilayah kerja Puskesmas Harapan Baru, Samarinda.

Metode: Penelitian ini merupakan jenis penelitian retrospektif dengan desain case control. Data dikumpulkan dengan wawancara semi-terstruktur dengan ibu balita menggunakan lembar kuesioner. Terdapat 19 sampel pada masing-masing kelompok kasus dan kontrol yang dipilih menggunakan purposive sampling. Sehingga, total sampel: 38 dengan uji statistik chi square untuk kualitas sarana sanitasi dan perilaku penghuni; uji fisher untuk CTPS ibu.

Hasil: Ada hubungan antara kualitas sarana sanitasi $(p=0,000 ; \mathrm{OR}=31,875 ; \mathrm{CI} 95 \%=5,093-199,480)$; perilaku penghuni $(\mathrm{p}=0,000$; OR $=18,417$; CI $95 \%=3,182-106,585)$ dengan kejadian stunting. Tidak ada hubungan antara kualitas CTPS yang dimiliki Ibu dengan kejadian stunting $(\mathrm{p}=0,116 ; \mathrm{OR}=3,923$; CI $95 \%=0,678-22,705)$. Namun ketiga variabel tersebut merupakan faktor risiko kejadian stunting karena memiliki OR $>1$.

Simpulan: Kualitas sarana sanitasi dan perilaku penghuni memiliki hubungan dengan kejadian stunting dan merupakan faktor risiko. Kualitas CTPS ibu tidak memiliki hubungan dengan kejadian stunting tetapi merupakan faktor risiko.
\end{abstract}

Kata kunci: stunting; sarana sanitasi; perilaku penghuni; CTPS; batita

\section{ABSTRACT}

Title: Relationship Between Quality Of Sanitation Infrastructures, Human Behavior, Mothers' Handwashes, To Stunting Rate For Children Age 6-24 Months

Background: A place is called as region which has chronic malnutrition problem if the prevalency of stunting children is equal to or more than $20 \%$. In 2017, it was increased to $29,6 \%$. It is dominated by the children under two years old. Samarinda also has prevalency of stunting children under two above $20 \%$. There are lots of determinant factors which coud caused stunting, but more study is needed about sanitation infrastructures, human behavior, and and mothers' hand washes.The aim or this research is to proof the relation of about 
sanitation infrastructures, human behavior, and and mothers' hand washes to stunting status of children age 624 months in two districts which are the region of Puskesmas Harapan Baru

Methods: This is a retrospective case-control study. Data were collected thorough semi-structure interview with mothers. The samples are 19 for each group, using purposive sampling. The total samples: 38 . Chi square test was used to test the relationship of quality sanitation infrastructures; residents' behaviour to stunting. Fisher test was used to exam the relationship of the mothers' hand wash quality.

Results: The quality of sanitation infrastructures ( $p=0,000 ; O R=31,875 ;$ CI 95\% $=5,093-199,480)$; residents' behavior ( $p=0,000 ; O R=18,417 ; C I$ 95\% $=3,182-106,585)$ had relationship to stunting. The quality of mothers' hand washes had no relationship to stunting with $p=0,116 ;$ OR $=3,923 ;$ CI 95\%=0,67822,705. However, three of them were risk factors of stunting since their $O R>1$.

Conclusion: The quality of sanitation infrastructures; residents' behaviour had relationship and were risk factors to stunting. The quality of mothers' hand washes had no relationship, but still a risk factor to stunting.

Keywords: stunting; sanitation infrastructures; residents' behaviour; hand washes

\section{PENDAHULUAN}

Terdapat 155 juta anak berusia kurang dari lima tahun (balita) yang stunting di dunia dengan luas mayoritas di South-Central Asia dan Sub-Sahara Africa. Persentase balita stunting di Asia mencapai $70 \%$ dari total balita stunting pada tahun 2017 di dunia. Indonesia merupakan negara yang memiliki kasus stunting terbanyak di asia tenggara ${ }^{1} .1$ dari 3 anak di Indonesia berisiko stunting akibat tinggal di lingkungan yang memiliki kondisi sanitasi yang buruk. Stunting tidak hanya disebabkan oleh satu faktor tetapi disebabkan oleh banyak faktor yang saling berhubungan satu dengan lain. Kualitas kesehatan lingkungan yang erat kaitanya dengan sanitasi lingkungan dan higiene pola asuh dinyatakan termasuk dalam faktor yang memengaruhi stunting ${ }^{2}$. Terdapat berbagai macam faktor yang mempengaruhi stunting. Stunting dapat diakibatkan oleh kekurangan asupan zat gizi makro dan mikro dalam jangka waktu yang lama, selain itu dipengaruhi oleh faktor lingkungan, Intrauterine Growth Retardation (IUGR) dan sosial ekonomi ${ }^{3}$

Anak stunting adalah anak yang memiliki tinggi badan lebih pendek dibandingkan dengan anak seusianya. Tinggi badan anak stunting kurang dari 2SD (Standar Deviasi) berdasarkan indeks $\mathrm{TB} / \mathrm{U}^{4,5}$. Gangguan pertumbuhan seperti stunting merupakan kejadian yang sangat umum terjadi pada usia awal kehidupan balita. Jika keadaan berlanjut dapat menyebabkan gagal tumbuh (growth failure). Kegagalan pada pertumbuhan linear ditunjukkan dengan rendahnya tinggi badan dan nilai Z-Score menurut indeks $\mathrm{TB} / \mathrm{U}$ dibandingkan dengan anak seusianya ${ }^{6}$.

Indonesia menempati posisi negara yang memiliki jumlah kasus stunting terbanyak se Asia Tenggara dan dinyatakan sebagai negara dengan sanitasi terburuk ke dua di dunia. Selain itu, terdapat 15 sampai 22 anak berusia di bawah lima tahun di Indonesia yang meninggal akibat diare dalam setiap jam yang diakibatkan kebersihan dan sanitasi lingkungan yang buruk. Cuci tangan pakai sabun dapat menurunkan risiko diare hingga $45 \%$ dan mengurangi risiko stunting $15 \%$. Baduta yang menderita diare memiliki risiko untuk mengalami stunting lebih tinggi dibanding baduta yang tak menderita stunting ${ }^{7}$.

Hasil pemantauan Status Gizi (PSG) 2016 menunjukkan bahwa sebanyak $21,7 \%$ bayi usia di bawah dua tahun (Baduta) mengalami stunting (tinggi badan di bawah standar/pendek) menurut usianya. Namun, prevalensi balita stunting kembali naik menjadi $29,6 \%$ dalam PSG 2017. Angka tersebut terdiri dari $9,8 \%$ balita dengan kategori sangat pendek dan 19,8\% kategori pendek. Menurut standar WHO, suatu wilayah dikatakan mengalami masalah gizi akut bila prevalensi bayi stunting sama/lebih dari $20 \%$. Sehingga kasus baduta stunting layak untuk diangkat, untuk merekomendasikan intervensi yang tepat yang akan dilakukan ${ }^{8,9}$.

Prevalensi baduta stunting sendiri ialah $22,8 \%$ di Kalimantan Timur. Kalimantan Timur menempati posisi provinsi dengan jumlah kasus stunting terbanyak kelima di Indonesia ${ }^{10}$. Adapun prevalensi stunting pada bayi yang berusia dibawah dua tahun (baduta) di Samarinda mencapai 20,8\%. Kota Samarinda yang sebelumnya hanya memiliki 67 kasus baduta stunting di tahun 2016, menjadi memiliki 99 kasus baduta stunting di 2017. Persebaran batita stunting cenderung lebih banyak di daerah yang memiliki derajat kesehatan lingkungan lebih rendah. Berdasarkan Environmental Health Risk Assessment (EHRA) 2016 Dinas Kesehatan Kota Samarinda, tingkat perilaku Buang Air Besar Sembarangan (BABS) dan tidak memiliki kebiasaan mencuci tangan menggunakan sabun (Cuci Tangan Pakai Sabun/CTPS) di Kota Samarinda cukup rendah. Kelurahan Harapan Baru ialah salah satu wilayah kerja Puskesmas Harapan Baru yang memiliki risiko kesehatan lingkungan yang tinggi. ${ }^{11}$

Penelitian ini ditujukan untuk membuktikan adanya hubungan sarana sanitasi, perilaku penghuni, dan kebiasaan mencuci tangan oleh ibu terhadap kejadian stunting. Karakteristik yang dalam penelitian ini mengacu pada pedoman teknis penilaian rumah sehat dengan hanya mempertimbangkan aspek penilaian yang berkaitan dengan risiko diare, yaitu aspek sarana sanitasi dan perilaku penghuni. Adapun, karakteristik yang digunakan kualitas higiene pola 
asuh baik atau buruk yang dipakai dalam penelitian ini mengacu pada kebiasaan mencuci tangan ibu dari bayi yang menjadi obyek penelitian.

\section{MATERI DAN METODE}

Penelitian dilakukan di Bulan Agustus Tahun 2018 hingga September 2018. Penelitian dilakukan pada wilayah kerja Puskesmas Harapan Baru, Kota Samarinda. Puskesmas Harapan Baru hanya memiliki dua kelurahan sebagai wilayah kerja nya, yaitu
Kelurahan Harapan Baru dan Rapak Dalam. Kelurahan Rapak Dalam memiliki kualitas lingkungan yang cenderung lebih baik sedangkan Kelurahan Harapan Baru memiliki kualitas lingkungan yang lebih buruk menurut petugas Dinas Kesehatan Kota Samarinda ${ }^{11}$. Peta daerah penelitian dapat dilihat pada gambar berikut, titik biru menandakan posisi sampel kontrol dan titik merah menandakan posisi sampel kasus:

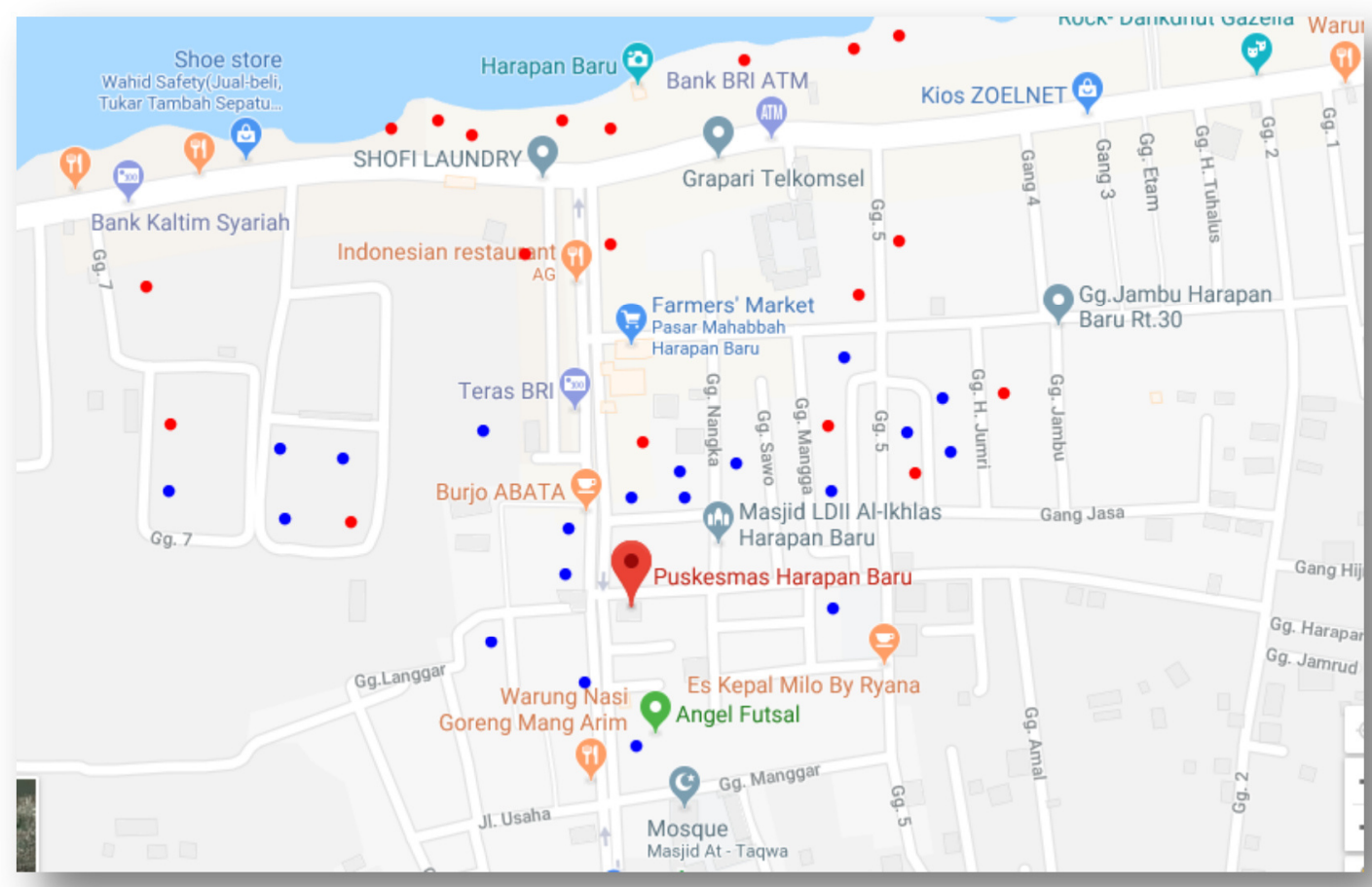

Gambar 1. Peta Sebaran Responden

Penentuan jumlah sampel dalam penelitian ini menggunakan rumus Lemeshow, dengan rumus sebagai berikut ${ }^{12}$ :

$$
\begin{gathered}
p_{2}=\frac{p_{1} O R}{1+p_{1}(O R-1)} \\
n^{\prime}=\frac{\left[Z_{1-\alpha / 2} \sqrt{(r+1) P(1-p)}+Z_{1-\beta} \sqrt{p_{1}\left(1-p_{1}\right)+p_{2}\left(1-p_{2}\right)}\right]^{2}}{r\left(p_{2}-p_{1}\right)^{2}} \\
n_{\text {eses }} \geq \frac{n^{\prime}}{4}\left(1+\sqrt{1+\frac{2(r+1)}{n r\left|p_{2}-p_{1}\right|}}\right)^{2}
\end{gathered}
$$

Nilai Alpha $(\alpha)$ yang digunakan ialah 0.05 sedangkan nilai Beta $(\beta)$ yang digunakan ialah 0.4 . Proporsi paparan pada kelompok kontrol diperkirakan $30 \%{ }^{13}$. Nilai OR yang digunakan sebesar 4,808 yang artinya adalah balita yang diasuh dengan higiene yang buruk akan berisiko mengalami stunting 4,808 kali lebih besar daripada balita yang diasuh dengan higiene yang baik $^{14}$. Penilaian higiene disini sudah termasuk sarana sanitasi dan perilaku penghuni rumah, serta kebiasaan CTPS. Rasio yang digunakan untuk kasus:kontrol ialah 1:1, dengan koefisien interval (CI)
95\%. Penghitungan dilakukan dengan menggunakan aplikasi Sample Size yang keakuratannya telah diakui oleh WHO. Hasil dari penghitungan, disarankan jumlah sampel sebesar 19 kasus dan 19 kontrol.

Responden dalam penelitian ini adalah ibu dari anak yang terpilih menjadi subjek penelitian yang bersedia mengisi lembar persetujuan menjadi responden. Besar objek penelitian sebanyak 38 anak, dengan 19 anak untuk masing-masing kelompok kasus dan kontrol, dengan kriteria:

1. Kriteria inklusi kasus

Kriteria inklusi kasus adalah krieria yang harus dipenuhi objek penelitian yang bersedia untuk menjadi sampel penelitian untuk kelompok kasus. Berikut kriteria inklusi yang diterapkan dalam penelitian ini:

a. Ibu bayi yang berusia 6-24 bulan yang memiliki kartu menuju sehat dan bersedia menjadi responden

b. Bayi tidak menderita penyakit kronis selama tiga bulan terakhir 
c. Bayi dan ibu telah bertempat tinggal di Kelurahan Harapan Baru minimal dua tahun terakhir, yang berlokasi di atas air dan rawan banjir.

d. Memiliki kartu menuju sehat.

e. Bayi sedang atau pernah menderita stunting dalam kurun 3 bulan terakhir.

2. Kriteria inklusi kontrol

Kriteria inklusi kontrol adalah krieria yang harus dipenuhi objek penelitian yang bersedia untuk menjadi sampel penelitian untuk kelompok kontrol. Berikut kriteria inklusi yang diterapkan dalam penelitian ini:

a. Ibu bayi yang berusia 6-24 bulan yang memiliki kartu menuju sehat dan bersedia menjadi responden

b. Bayi tidak menderita penyakit kronis selama tiga bulan terakhir

c. Bayi dan ibu telah bertempat tinggal di Kelurahan Rapak Dalam minimal dua tahun terakhir, yang berlokasi di atas darat dan tidak rawan banjir.

d. Memiliki kartu menuju sehat.

e. Bayi tidak sedang atau tidak pernah menderita stunting dalam kurun 3 bulan terakhir.

3. Kriteria eksklusi

Kriteria eksklusi adalah kriteria yang menyebabkan objek tidak dijadikan sampel penelitian. Objek tidak dijadikan sebagai objek penelitian jika tidak memiliki satu atau lebih dari satu kriteria inklusi, atau jumlah sampel telah memenuhi syarat. Adapun kriteria ekslusi tambahan ialah:

a. Ibu tidak merupakan ibu rumah tangga

b. Ibu menitipkan anaknya untuk diasuh oleh orang lain

Kualitas sarana sanitasi ditentukan dengan teknik skoring. Hasil skoring mengelompokkan sarana sanitasi menjadi dua kategori; 1) Tidak memenuhi syarat; 2) Memenuhi syarat. Untuk memenuhi syarat, jawaban kuesioner pada tabel sarana sanitasi harus memiliki skor yang sama dengan atau melebihi $80 \%$ dari skor maksimum, yaitu 300. Penilaian kualitas perilaku penghuni juga menggunakan skala skoring berdasarkan pedoman teknis penilaian rumah sehat, untuk memenuhi syarat pada perilaku penghuni perlu memiliki skor $\geq 80 \%$ dari nilai maksimum, yaitu dengan skor $\geq 352$. Hal tersebut sesuai dengan panduan peniaian rumah sehat yang diterbitkan pemerintah $^{15}$. Adapun kualitas CTPS ibu dikategorikan tidak memenuhi syarat jika terdapat satu atau lebih kriteria dalam kuesioner yang tidak dipenuhi.

Sampel telah dibedakan dalam kelompok kasus dan kontrol, selanjutnya ketiga variabel diukur dengan menggunakan kuesioner dan menanyakan dengan menggunakan kalimat yang menanyakan masa lalu, sebelum objek ditetapkan stunting dan tidak stunting. Penelitian ini merupakan penelitian kuantitatif dengan metode deskriptif analitik. Uji yang dilakukan adalah uji hipotesis antara variabel kategorik yang tidak berpasangan. Masing-masing variabel independen diujikan satu per satu dengan variabel dependen dengan menggunakan uji chi square jika memenuhi syarat chi square, atau menggunakan uji Fisher jika tak memenuhi syarat Uji fisher ${ }^{16} . \alpha=0,05$

\section{HASIL DAN PEMBAHASAN}

Terdapat 14 sub-variabel yang ditanyakan untuk menentukan kualitas sarana sanitasi rumah, dan perilaku penghuni di rumah yang ditempati oleh responden bersama bayinya, serta kualitas CTPS ibu. Berikut interpretasi distribusi responden berdasarkan 14 sub-variabel pada tabel 1.

Pada distribusi umur, tidak terlihat perbedaan yang mencolok pada kelompok kasus, terdapat tiga kategori kelompok umur yang memiliki persentase $21,1 \%$ pada kelompok kasus. Sementara, pada kelompok kontrol, kategori kelompok umur 22-25 memiliki persentase terbanyak, yaitu $42,1 \%$ dari seluruh responden kelompok kontrol. Selain itu, pada distribusi responden berdasarkan riwayat pendidikan terakhir, terlihat perbedaan mencolok antara kedua kelompok. Kelompok kasus didominasi oleh ibu-ibu yang tidak tamat SD, yaitu $36,8 \%$ dari total responden. Sedangkan pada kelompok kontrol, didominasi oleh lulusan SMA, sebanyak 57,9\%.

Berdasarkan tabel 1 pada supplementary file, pada variabel kualitas sarana sanitasi, terdapat empat sub-variabel yang dinilai; 1) Kepemilikan sarana air bersih; 2) Kepemilikan sarana jamban; 3) Kepemilikan sarana pembuangan air limbah; dan 4) Kepemilikan tempat sampah. Terdapat perbedaan yang paling mencolok pada sub variabel kepemilikan jamban. Di antara seluruh sub-variabel kualitas sarana sanitasi, pada kelompok kasus, kepemilikan jamban adalah yang paling banyak bermasalah. Terdapat $68,4 \%$ dari kelompok kasus yang memiliki jamban leher angsa tetapi tidak ada tutup dan disalurkan langsung ke sungai. Tidak ada responden dari kelompok kasus yang memiliki jamban leher angsa bertutup dan disalurkan langsung ke septic tank. Sedangkan pada kelompok kasus, tidak terdapat responden yang memiliki jamban leher angsa yang tak bertutup dan disalurkan langsung ke sungai. 63,2\% responden dari kelompok kasus memiliki jamban leher angsa yang bertutup dan disalurkan langsung ke septictank.

Adapun pada variabel kualitas perilaku penghuni, memiliki lima sub-variabel; yang paling bermasalah pada kelompok kasus ialah kebiasaan membersihkan halaman rumah. Seluruh responden dari kelompok kasus memiliki kebiasaan terkadang membersihkan halaman rumah. Sedangkan pada kelompok kontrol, terdapat 52,6\% responden memiliki kebiasaan terkadang membersihkan halaman rumah dan 47,6\% responden yang memiliki kebiasaan membersihkan halaman rumah setiap hari. Selain itu, pada kelompok kasus, terdapat lebih banyak responden yang memiliki 
kebiasaan membuang tinja balita sembarangan, dibanding kelompok kontrol. 89,5\% responden dari kelompok kasus memiliki kebiasaan membuang tinja bayi/ balita di sungai/ kolam/ kebun/ sembarangan dan $10,5 \%$ yang membuang tinja bayi/balita ke jamban. Sedangkan pada kelompok kontrol, terdapat $68,4 \%$ yang membuang tinja bayi/balita di jamban setiap hari dan $31,6 \%$ yang membuang tinja bayi/balita ke sungai/kolam/kebun/sembarangan. Hal tersebut dapat berhubungan dengan kondisi jamban yang mereka miliki.

Pada variabel kualitas variabel CTPS ibu, terdapat tiga sub-variabel; 1) Kebiasaaan CTPS ibu sebelum mengolah pangan bayi/balita; 2) Kebiasaan CTPS ibu sebelum memberi makanan pada bayi/balita; 3) Kebiasaan CTPS ibu setelah menggunakan WC. Pada ketiga sub-variabel tersebut, tidak ditemukan perbedaan persentase jawaban. Adapun kebiasaan yang biasa dilakukan pada ketiga sub-variabel tersebut, 89,5\% responden pada kelompok kasus memiliki kebiasaan CTPS tanpa menggunakan sabun, sedangkan pada kelompok kontrol beberapa responden telah menggunakan sabun, namun $68,4 \%$ belum melakukan CTPS dengan langkah yang benar. Hanya 31,6\% responden dari kelompok kontrol dan $10,5 \%$ responden dari kelompok kasus yang memiliki kebiasaan CTPS setiap saat, menggunakan sabun, di bawah air yang mengalir, dan sesuai dengan langkah CTPS yang benar.

Berdasarkan tabel 2, hasil analisis, diketahui $\mathrm{p}=$ 0,$000 ;$ OR $=31,875 ;$ CI $95 \%=5,093-199,480$, yang menunjukkan ada hubungan bermakna antara status sarana sanitasi dengan kejadian stunting. Artinya, anak-anak kelompok usia 6-24 bulan yang tinggal di rumah yang memiliki sarana sanitasi yang tidak memenuhi syarat, berisiko 31,875 kali untuk mengalami stunting. Sehingga kualitas sarana sanitasi merupakan faktor risiko kejadian stunting pada anakanak kelompok usia 6-24 bulan

Pada variabel perilaku penghuni, berdasarkan hasil analisis, diketahui $\mathrm{p}=0,000$; $\mathrm{OR}=18,417$; CI 95\% $=$ 3,182-106,585, yang menunjukkan ada hubungan bermakna antara kualitas perilaku penghuni dengan kejadian stunting. Artinya, anak-anak kelompok usia 6-24 bulan yang tinggal di rumah yang memiliki perilaku penghuni yang tidak memenuhi syarat, berisiko 18,417 kali untuk mengalami stunting. Sehingga kualitas sarana perilaku penghuni merupakan faktor risiko kejadian stunting pada anakanak kelompok usia 6-24 bulan.

Hasil analisis kualitas CTPS ibu menggunakan uji fisher, diketahui CTPS ibu memiliki $\mathrm{p}=0,116$; OR= 3,923; CI $95 \%=0,678-22,705$, yang menunjukkan tidak ada hubungan bermakna antara kualitas perilaku penghuni dengan kejadian stunting. Akan tetapi, CTPS ibu yang tak memenuhi syarat termasuk faktor risiko kejadian stunting karena memiliki OR $>1$. Artinya, anak-anak kelompok usia 6-24 bulan yang tinggal di rumah yang memiliki kualitas CTPS Ibu yang tidak memenuhi syarat, berisiko 3,923 kali untuk mengalami stunting. Sehingga kualitas CTPS ibu merupakan faktor risiko kejadian stunting pada anakanak kelompok usia 6-24 bulan.

Tabel 1. Hasil Analisis Hubungan Antara Kualitas Sarana Sanitasi, Perilaku Penghuni dan CTPS Ibu dengan Status Stunting

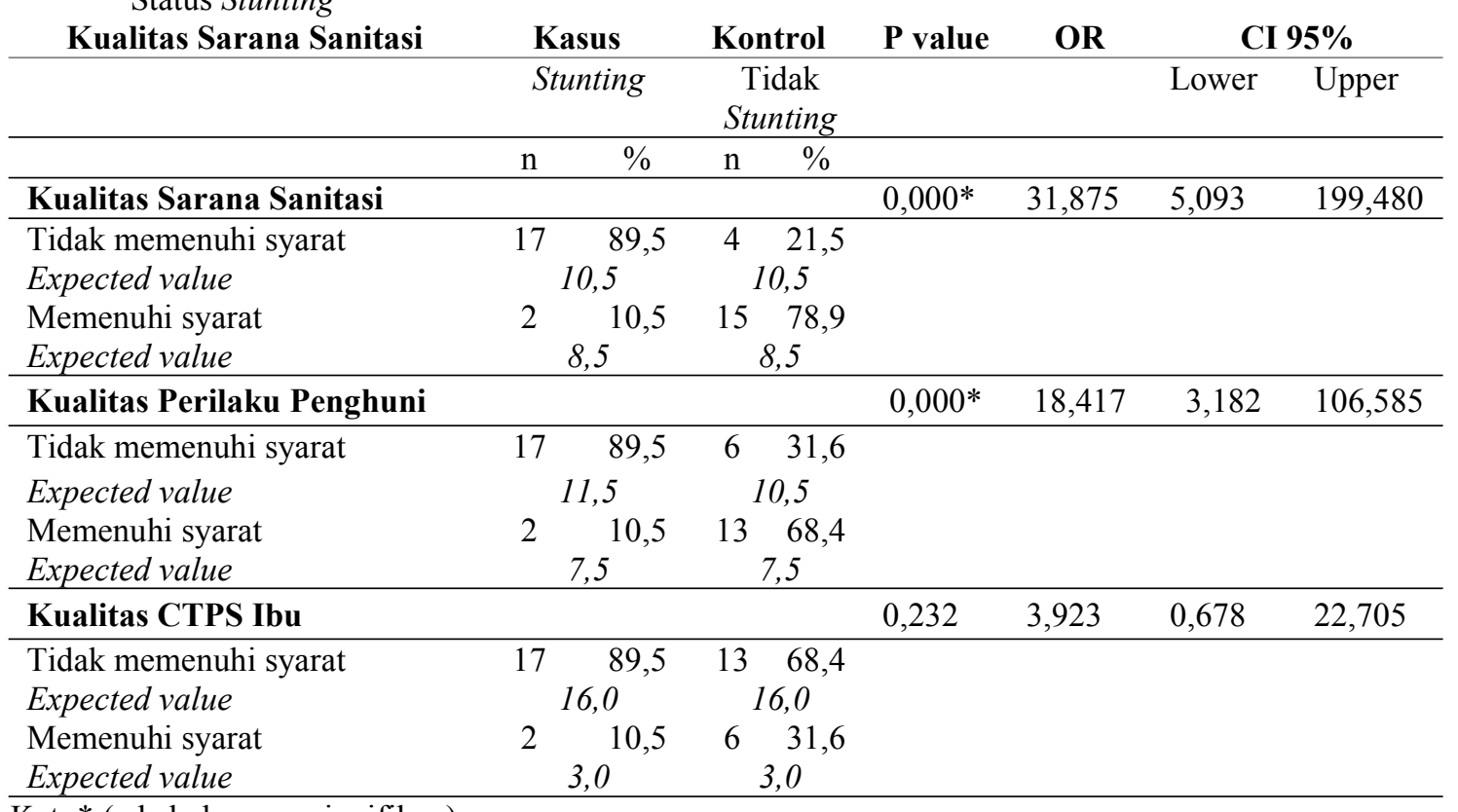

Ket: * (ada hubungan signifikan)

Expected value yang berwarna merah menunjukkan penggunaan uji fisher

HUBUNGAN KUALITAS SARANA SANITASI DENGAN STUNTING
Sanitasi adalah usaha kesehatan masyarakat yang menitikberatkan pada pengawasan terhadap berbagai 
faktor lingkungan yang mempengaruhi atau mungkin mempengaruhi derajat kesehatan manusia. Interaksi antara faktor lingkungan (environment), pejamu (host) dan penyebab penyakit (agent) telah sangat kita pahami interaksi dan bukti ilmiahnya. Beberapa penelitian antara lain membuktikan kondisi ini, sebagaimana penelitian yang menunjukkan bahwa tempat pembuangan tinja yang tidak sanitair akan meningkatkan risiko terjadinya diare pada balita sebesar 2,55 kali lipat dibandingkan dengan yang sanitair ${ }^{17}$.

Berdasarkan hasil uji Chi Square, kualitas sarana sanitasi memiliki $p=0,000$, sehingga terbukti terdapat hubungan antara kualitas sarana sanitasi dengan kejadian stunting. Penelitian ini sejalan dengan penelitian Ahmad Syafiq (2007), yang menyebutkan faktor kesehatan lingkungan memengaruhi kasus stunting ${ }^{18}$. Hasil dari penelitian ini juga membuktikan bahwa kerangka teori UNICEF masih valid.

Dari 19 anak yang mengalami stunting 89,5\% diantaranya tinggal di rumah yang memiliki kualitas sarana sanitasi tidak memenuhi syarat untuk dinyatakan sehat, dua diantaranya memiliki kualitas sarana sanitasi yang memenuhi syarat. Dua anak yang memiliki kualitas sarana sanitasi yang memenuhi syarat namun tetap mengalami stunting dapat disebabkan oleh faktor lain yang merupakan faktor langsung maupun faktor tidak langsung lainnya, seperti variabel independen lainnya yang diteliti maupun selain variable independen yang diteliti, seperti Berat Bayi Lahir Rendah (BBLR), dan status ekonomi.

Penelitian dilakukan di wilayah Kota Bogor pada bulan Desember 2015 sampai dengan Maret 2016 menunjukkan, terdapat hubungan yang positif dan signifikan antara berat bayi lahir rendah $(\mathrm{BBLR})^{19}$.Pada penelitian observasional dengan desain case-control pada balita usia 2-3 tahun di wilayah kecamatan Semarang Timur, hasil analisis multivariat menunjukkan bahwa faktor risiko stunting pada balita usia 2-3 tahun adalah status ekonomi keluarga yang rendah $(\mathrm{p}=0,032 ; \mathrm{OR}=4,13)^{20}$.

Pada penelitian ini, yang menjadi permasalahan terbesar di sarana sanitasi adalah kepemilikan jamban yang tidak memenuhi syarat kesehatan. Pada kelompok kasus, ditemukan kebanyakan dari kelompok kasus memiliki jamban yang membuang kotorannya langsung ke sungai. Disusul dengan kepemilikan sumber air bersih yang mengandalkan air sungai untuk kegiatan mandi cuci kakus (MCK).

Penelitian ini sejalan dengan penelitian Torlesse, et al (2016) yang menunjukkan ada hubungan antara sarana sanitasi seperti jamban terhadap kejadian stunting dengan $\mathrm{p}<0,001$ yang menunjukkan berhubungan signifikan nya kedua hal tersebut terhadap kejadian stunting. Akan tetapi, penelitian tersebut menunjukan tidak ada hubungan antara sumber air bersih dengan kejadian stunting dengan $\mathrm{p}=0,23^{21}$. Selain itu, Nkurunziza, et al (2017) menyatakan sumber air tidak berhubungan dengan stunting dengan $\mathrm{p}=0,46$. Kedua penelitian tersebut bersifat cross sectional dan tidak menilai dan menguji hubungan sarana sanitasi dangan kejadian stunting langsung secara keseluruhan, akan tetapi komponen sarana sanitasi dipecah dan diuji secara terpisah ${ }^{22}$.

\section{HUBUNGAN KUALITAS PERILAKU PENGHUNI TERHADAP KEJADIAN STUNTING}

Perilaku mempunyai pengaruh yang besar terhadap derajat kesehatan masyarakat. Faktor lingkungan meliputi lingkungan fisik, biologik dan sosio-kultural. Faktor perilaku antara lain higiene perseorangan (personal hygiene). Perilaku penghuni dapat memengaruhi derajat sehat tidaknya rumah ${ }^{23}$. Kuesioner yang digunakan bersumber dari kuesioner penilaian rumah sehat, namun yang diambil hanyalah yang berkaitan dengan kerangka teori stunting untuk mengurangi bias.

Berdasarkan uji chi square kualitas perilaku penghuni untuk rumah sehat memiliki $\mathrm{p} \mathrm{p}=0,000$; $\mathrm{OR}=18,417 ;$ CI $95 \%=3,182-106,585$, yang menunjukkan ada hubungan bermakna antara kualitas perilaku penghuni dengan kejadian stunting. Artinya, anak-anak kelompok usia 6-24 bulan yang tinggal di rumah yang memiliki perilaku penghuni. Penelitian ini sejalan dengan hasil Aramico, Sudargo, \& Susilo (2013) yang menyebutkan ada hubungan yang signifikan antara perilaku penghuni terhadap kejadian stunting ${ }^{24}$.

Terdapat19 anak yang mengalami stunting 89,5\% diantaranya tinggal di rumah yang memiliki kualitas perilaku penghuni yang tidak memenuhi syarat untuk dinyatakan sehat, dua diantaranya memiliki kualitas perilaku penghuni yang memenuhi syarat. Dua anak yang memiliki kualitas perilaku penghuni yang memenuhi syarat namun tetap mengalami stunting dapat disebabkan oleh faktor lain yang merupakan faktor langsung maupun faktor tidak langsung lainnya, seperti variabel independen lainnya maupun selain variabel independen yang diteliti, seperti penghasilan orangtua dan pola makan.

Pada penelitian Aramico, Sudargo, \& Susilo (2013) yang bersifat observasional analitik dengan rancangan cross sectional dan metode kuantitatif, menunjukkan ada hubungan antara pendidikan ibu dengan status gizi $(\mathrm{p}<0,001) \quad \mathrm{OR}=4,06$, ada hubungan antara pendidikan ayah dengan status gizi $(\mathrm{p}<0,001)$ $\mathrm{OR}=3,37$, ada hubungan antara jumlah balita dalam keluatga dengan status gizi $(p=0,007) \mathrm{OR}=2,71$. Ada hubungan antara pendapatan orang tua dan status gizi $(\mathrm{p}<0,001) \mathrm{OR}=7,8^{24}$.

Pada penelitian ini, yang menjadi permasalahan terbesar di perilaku penghuni adalah kebiasaan membuang tinja anak dengan sembarangan. Pada kelompok kasus, ditemukan kebanyakan dari kelompok kasus memiliki tinja anak langsung ke sungai, beberapa responden membuang ke tempat sampah tanpa membuang tinja nya terlebih dahulu ke jamban. Disusul dengan kebiasaan membuang sampah 
pada tempat sampah. Hal tersebut juga sangat memengaruhi derajat kesehatan lingkungan dan dapat mengakibatkan anak mudah terkena penyakit menular akibat air yang digunakan maupun lalat yang beterbangan di lingkungan mereka, sehingga akhirnya membuat anak-anak mereka mengalami stunting. Hal tersebut sesuai dengan penelitian Desyanti \& Nindya (2017) yang menyatakan sebagian besar balita stunting mengalami kejadian diare yang sering yaitu lebih dari dua kali dalam tiga bulan terakhir, sedangkan pada kelompok tidak stunting sebagian besar jarang mengalami diare ${ }^{25}$.

Penelitian ini menunjukkan perilaku penghuni memiliki hubungan dengan kejadian stunting juga sejalan dengan penelitian Oktaviana (2016) yang menyatakan ada hubungan antara kejadian stunted dengan perilaku higiene $(p=0,017)^{26}$. Hasil penelitian juga sejalan dengan yang dilakukan Renyoet et al (2010) tentang hubungan praktik higiene dengan kejadian stunted anak usia 6-23 bulan dengan $p=0,000$, sehingga dikatakan terdapat hubungan antara praktik higiene dengan kejadian stunted ${ }^{27}$.

Pengetahuan yang cukup mengenai praktik higiene perilaku penghuni yang benar dan manfaatnya dapat mempengaruhi ibu dalam melakukan praktek hygiene yang benar. Peningkatan pengetahuan tidak mutlak diperoleh dari pendidikan formal saja, akan tetapi dapat diperoleh melalui. Pengetahuan seseorang terhadap objek mengandung dua aspek, yaitu aspek positif dan aspek negatif. Kedua aspek tersebut menentukan sikap dan sikap menentukan perilaku. Pendidikan memengaruhi aspek pengetahuan, meskipun pengetahuan tak hanya dapat didapatkan melalui pendidikan formal ${ }^{28}$.

Berdasarkan tabel 1 mengenai distribusi responden berdasarkan tingkat pendidikan terakhir, dari 19 responden pada kelompok kasus, 36,8\% menyatakan tidak tamat SD. Sedangkan pada kelompok kontrol, tidak terdapat responden yang menyatakan tidak tamat SD. Tabel 4.16 menunjukkan dari 19 responden pada kelompok kasus 89,5\% memiliki kualitas perilaku penghuni yang tidak memenuhi syarat untuk dinyatakan tidak berisiko. Sedangkan pada kelompok kontrol, hanya $31,6 \%$ dari 19 responden yang memiliki kualitas perilaku penghuni yang tidak memenuhi syarat untuk dinyatakan tidak berisiko. Hal tersebut menunjukkan adanya kemungkinan terdapat hubungan antara pengetahuan/pendidikan responden terhadap perilaku responden untuk memiliki kualitas perilaku penghuni yang memenuhi syarat untuk dinyatakan tidak berisiko.

\section{HUBUNGAN KUALITAS CTPS IBU TERHADAP KEJADIAN STUNTING}

Kebiasaan CTPS oleh ibu termasuk pola asuh yang berhubungan dengan higiene dan kesehatan. Kebiasaan mencuci tangan juga merupakan faktor penentu derajat risiko kesehatan lingkungan. Cuci tangan pakai sabun dapat menurunkan risiko diare hingga $45 \%$ dan mengurangi risiko stunting $15 \%{ }^{29}$.
Berdasarkan uji Fisher kualitas kebiasaan CTPS ibu memiliki $\mathrm{p}=0,116$; OR=3,923; CI 95\%=0,67822,705 , yang menunjukkan ada hubungan bermakna antara kualitas perilaku penghuni dengan kejadian stunting. Akan tetapi, CTPS ibu yang tak memenuhi syarat termasuk faktor risiko kejadian stunting karena memiliki OR $>1$. Artinya, anak-anak kelompok usia 624 bulan yang tinggal di rumah yang memiliki kualitas CTPS Ibu yang tidak memenuhi syarat, berisiko 3,923 kali untuk mengalami stunting. Kualitas CTPS dalam penelitian ini tidak memiliki hubungan dengan kejadian stunting, dikarenakan pada kelompok kontrol memiliki $68,4 \%$ responden yang tidak memiliki kualitas kebiasaan CTPS yang memenuhi syarat, persentase tersebut tak terlalu berbeda dengan kelompok kasus yang memiliki $89,5 \%$ responden yang tidak memiliki kualitas kebiasaan CTPS yang memenuhi syarat. Selain itu, dalam penelitian ini, ditemukan faktor sarana sanitasi dan perilaku penghuni memiliki OR yang lebih besar dibanding kualitas CTPS ibu, yaitu 31,875 dan 18,417. Kelompok kasus yang tidak memiliki kualitas kebiasaan CTPS yang memenuhi syarat dapat terpapar oleh faktor penyebab stunting yang lain, seperti kualitas sarana sanitasi yang tidak memenuhi syarat dan perilaku penghuni yang tidak memenuhi syarat, sehingga membuat anak-anak mereka lebih berisiko stunting dan mengalami stunting.

Hasil ini tidak sejalan dengan penelitian yang menyebutkan ada hubungan yang signifikan antara higiene terhadap kejadian stunting ${ }^{24}$. CTPS merupakan salah satu praktek higiene perorangan dalam hal pola asuh yang berkontribusi terhadap kejadian diare ${ }^{12}$. Kejadian diare dinyatakan sebagai salah satu faktor risiko yang berhubungan dengan kejadian stunting dengan $\mathrm{OR}=1,17 \mathrm{Kenya}^{31}$.

Meskipun tidak terbukti terdapat hubungan antara kebiasaaan CTPS ibu dengan kejadian stunting pada anak usia 6-24 bulan, tetapi berdasarkan tabel 2 yang menunjukkan hasil uji hubungan antara kebiasaan CTPS ibu dengan kejadian stunting ditemukan 89,5\% responden pada kelompok kasus, hanya sekedar membasahi tangan dengan air tanpa menggunakan sabun. Hal tersebut memengaruhi kualitas kebersihan ibu saat berhadapan dengan anak dan dapat mengakibatkan anak mudah terkena penyakit menular akibat tangan ibu yang kurang bersih digunakan untuk mengurus anak secara langsung, sehingga akhirnya membuat anak-anak mereka berisiko terserang oleh kuman yang menempel pada ibu mereka, sehingga menyebabkan penyakit infeksi seperti diare, yang juga dapat membuat mereka mengalami stunting.

Hasil penelitian ini tidak sejalan dengan penelitian Torlesse, et al (2016) yang menyatakan kebiasaan CTPS memiliki hubungan yang signifikan dengan kejadian stunting dan termasuk faktor risiko kejadian stunting dengan $\mathrm{p}=0,003$ dan $\mathrm{OR}=2,04^{21}$. Penelitian tersebut merupakan jenis penelitian cross sectional dan data dikumpulkan secara retrospektif. Sedangkan 
penelitian ini bersifat retrospektif menggunakan jenis penelitian case control.

\section{KETERBATASAN PENELITIAN}

Penelitian ini dilakukan dengan retrospektif yang mengandalkan ingatan responden dan responden tak jarang lupa bila ditanyakan kebiasaan lama sebelum anak mereka dikatakan mengalami stunting atau tidak di usia saat mereka menjadi responden. Namun keterbatasan tersebut, dapat ditangani dengan teknik wawancara yang fleksibel dan tak baku dengan instrument yang ada untuk memancing ingatan responden. Disarankan pemerintah bersama puskesmas setempat melakukan penelitian yang lebih komprehensif dan bersifat prospektif untuk mendukung hasil penelitian ini dan menjadi dasar pembuatan program untuk pengentasan stunting di wilayah mereka.

\section{SIMPULAN}

Penelitian ini menghasilkan tiga kesimpulan, yaitu; 1) Ada hubungan antara kualitas sarana sanitasi dengan kejadian stunting dengan $\mathrm{p}=0,000$; OR $=$ 31,875; CI 95\% = 5,093-199,480 dan kualitas sarana sanitasi merupakan faktor risiko kejadian stunting; 2) Ada hubungan antara perilaku penghuni dengan kejadian stunting dengan $\mathrm{p}=0,000 ; \mathrm{OR}=18,417$; CI $95 \%=3,182-106,585$ dan perilaku penghuni merupakan faktor risiko stunting; 3) Tidak ada hubungan antara kebiasaan CTPS yang dimiliki Ibu dengan kejadian stunting dengan $\mathrm{p}=0,116$; $\mathrm{OR}=$ 3,923; CI $95 \%=0,678-22,705$ dan kebiasaan CTPS merupakan faktor risiko stunting.

\section{DAFTAR PUSTAKA}

1. UNICEF. Multi-sectoral Approaches to Nutrition : Nutrition-Specific and Nutrition- Sensitive Interventions to Accelerate Progress. 2017.

2. UNICEF. Ringkasan Kajian Gizi. Jakarta: Pusat Promosi Kesehatan- Kementerian. 2012.

3. Monteiro CA, Benicio MH, Conde WL, Konno S, Lovadino AL, Barros AJ, Victora CG. Narrowing socioeconomic inequality in child stunting: the Brazilian experience, 1974-2007. Bull World Health Organ. 2010 Apr;88(4):305-11

4. Bappenas RI Kerangka Kebijakan Gerakan Nasional Percepatan Perbaikan Gizi dalam Rangka Seribu Hari Pertama Kehidupan. 2013.

5. Subekti S, Yulia C. Pengetahuan Gizi dan Pola Asuh Ibu Anak Balita Gizi Kurang di Kelurahan Pasteur Kecamatan Sukajadi Bandung. INVOTEC. 2015; VIII(1), 58-74.

6. Kementerian Kesehatan RI. InfoDATIN: Situasi Balita Pendek. 2016

7. World Health Organization. Childhood Stunting: Challenges and Opportunities Report. 2012.
8. Kementerian Kesehatan RI. Hasil Pemantauan Status Gizi (PSG) 2016. 2017.

9. Kementerian Kesehatan RI. (2018). Hasil Pemantauan Status Gizi (PSG) 2017

10. Kementerian Keuangan RI. Penanganan Stunting Terpadu Tahun 2018. Jakarta. 2018.

11. Puskesmas Harapan Baru. Personal Interview. Samarinda. 2018.

12. Siswosudarmo R. Pendekatan Praktis Penelitian Epidemiologi Klinis dan Aplikasi SPSS Untuk Analisis Statistika. Yogyakarta. 2015.

13. UNICEF. Improving Child Nutrition The achievable imperative for global progress. 2013.

14. Desyanti C,Nindya TS. Hubungan Riwayat Penyakit Diare dan Praktik Higiene dengan Kejadian Stunting pada Balita Usia 24-59 Bulan di Wilayah Kerja Puskesmas Simolawang, Surabaya. 2017. Amerta Nutrition. 2017. 1:243-251

15. Departemen Kesehatan RI. Pedoman Teknis Penilaian Rumah Sehat. Jakarta: Ditjen PP\&PL. 2007

16. Dahlan MS. Statistik.untu Kedokteran dan Kesehatan. Jakarta: Salemba Medika. 2012.

17. Utami RP, Suhartono, Nurjazuli, Kartini A, Rasipin. Faktor Lingkungan dan Perilaku yang Berhubungan dengan Kejadian Stunting pada Siswa SD di Wilayah Pertanian ( Penelitian di Kecamatan Bulakamba Kabupaten Brebes ). Jurnal Kesehatan Lingkungan Indonesia. 2013; 12(2), 127-131.

18. Syafiq A. Tinjauan atas kesehatan dan gizi anak usia dini, in Makalah pada Diskusi Peningkatan Kesehatan dan Gizi Anak Usia Dini, Bappenas. Jakarta: Departemen Gizi Kesehatan Masyarakat, FKMUI. 2007.

19. Rosha BC, Sisca D, Putri K, Yunita I., Putri S. Determinan Status Gizi Pendek Anak Balita dengan Riwayat Berat Badan Lahir Rendah (BBLR) di Indonesia ( Analisis Data Riskesdas 2007-2010 ). Jurnal Ekologi Kesehatan. 2013, September 3; 12 (3) : 195-205.

20. Kusuma KE. Faktor Risiko Kejadian Stunting pada Anak Usia 2-3 Tahun ( Studi di Kecamatan Semarang Timur ). Journal of Nutrition College. 2013; 2(4):523-530.

21. Torlesse H, Cronin AA, Sebayang SK, Nandy R. Determinants of Stunting in Indonesian Children: Evidence from A Cross-Sectional Survey Indicate A Prominent Role For The Water, Sanitation And Hygiene Sector in Stunting Reduction. BMC Public Health Journal. 2016; 16:669-. 
22. Nkurunziza S, Meessen B, Van J, Korachais C. Determinants of Stunting and Severe Stunting Among Burundian Children Aged 6-23 Months: Evidence from A National Cross-Sectional Household Survey, 2014. BMC Pediatrics. 2017; 17:176.

23. Notoatmodjo S. Ilmu Kesehatan Masyarakat. Jakarta: Rineka Cipta. 2007.

24. Aramico B, Sudargo T, Susilo J. Hubungan Sosial Ekonomi, Pola Asuh, Pola Makan dengan Stunting pada Siswa Sekolah Dasar di Kecamatan Lut Tawar, Kabupaten Aceh Tengah. Jurnal Gizi dan Dietetik Indonesia. 2013; 1(3), 121-130.

25. Desyanti C, Nindya TS. Hubungan Riwayat Penyakit Diare dan Praktik Higiene dengan Kejadian Stunting pada Balita Usia 24-59 Bulan di Wilayah Kerja Puskesmas Simolawang, Surabaya. Amerta Nutrition. 2017; 1(3):243-251.

26. Oktaviana H. Hubungan Pengetahuan Gizi dan Perilaku Higiene Sanitasi terhadap Kejadian stunted pada Balita Usia 7-24 Bulan di Desa Hargorejo Kulon Progo. 2016.
27. Renyoet BS, Hadju V, Rochimiwati SN. Hubungan Pola Asuh dengan Kejadian Stunting Anak Usia 6-23 Bulan di Wilayah Pesisir Kecamatan Tallo Kota Makassar. Al- Sihah: Public Health Science Journal. 2014; 6(2):424-436.

28. Olsa ED, Sulastri D, Anas E. Hubungan Sikap dan Pengetahuan Ibu terhadap Kejadian Stunting pada Anak Baru Masuk Sekolah Dasar di Kecamanatan Nanggalo. Jurnal Kesehatan Andalas. 2017; 6(3), 523-529.

29. WHO. Childhood Stunting: Challenges and opportunities. Report of a Promoting Healthy Growth and Preventing Childhood Stunting colloquium. Geneva: World Health Organization. 2014.

30. Dewi F, Rahayuningati S, Rohmawati N. Praktik Pola Asuh dan Status Gizi Anak Balita Usia 6-24 Bulan pada Masyarakat Suku Using Desa Kemiren Kecamatan Glagah , Kabupaten Banyuwangi. eJournal Pustaka Kesehatan. 2015; 3(3): 507-514. 